\title{
Paradigms for On-Line Learning: \\ A Case Study in the Design and Implementation of an Asynchronous Learning Networks (ALN) Course
}

\author{
John R. Bourne, Eric McMaster, Jennifer Rieger, and J. Olin Campbell \\ Center for Innovation in Engineering Education \\ Vanderbilt University \\ Nashville, TN 37235
}

\begin{abstract}
This paper examines paradigms used in on-line learning, with a specific emphasis on how to effectively employ asynchronous learning networks for delivery of on-line courses. Recent progress in ALNs is presented, methodologies for getting started in creating an ALN course given, and relationships between traditional teaching and learning methods and ALN-based courses discussed. To illustrate a specific ALN model, the paper presents a case study about the creation of an on-line course. The prospects for on-line education and the challenges that face the ALN field are considered.
\end{abstract}

\section{KEYWORDS}

\author{
ALN \\ Information Technology \\ Conferencing \\ Portfolios \\ Mentoring \\ On-Line Course
}

\section{INTRODUCTION}

Asynchronous Learning Networks (ALNs) provide the capability to learn anywhere and at any time. The acronym ALN might just as well be used to represent the term Anywhere/Anytime Learning Networks ${ }^{1}$. Both interpretations reflect and emphasize that ALNs are different from traditional distance learning methods (e.g., video broadcasting) because the learner can be anywhere and can learn at any time. While an ALN might be a correspondence course or a course offered by recording messages on answering machines, most modern interpretations link ALN with on-line or world-wide-web-based learning. The key ingredient of an ALN is the capability for learners to learn anywhere and at anytime and to be part of a community of learners. Modern implementations of ALN systems utilize conferencing systems and on-line reading materials and exercises.

In many curricula, the traditional classroom experience is best characterized as a "sage on the stage" activity. If the "sage" is simply transferred to a set of video and/or audio clips, we have a "sage in the box" that can be viewed from anywhere and at anytime. While capturing the traditional classroom experience in a box is readily understandable, ALN can be much more. We can add the capabilities of tying geographically distributed people together, facilitating learning with different modalities, permitting time and place shifting, rapid feedback, on-line simulations

\footnotetext{
${ }^{1}$ This distinction was made by Ralph Gomory, President of the Alfred P. Sloan Foundation in his opening remarks at the Second International ALN Conference, 1996.
} 
and laboratories and a host of yet unexplored capabilities. The potential of ALN for changing the way education is delivered and the way people learn is tremendous. In this paper we explore some early steps toward learning what the capabilities of ALN can be.

The cost effectiveness of ALNs is hypothesized to be much greater than the traditional lecture or laboratory model of instruction. Due to the nature of time shifting and the use of network-based support tools (e.g., computer conferencing), there is qualitative evidence that scale-up is possible. In this case, "scale-up" means being able to increase the student/faculty ratio while maintaining quality education. However, detailed studies that supply quantitative evidence to support the claim have not yet been accumulated. The rationale for the claim that scale-up is possible is (1) peer-topeer learning is enhanced through computer conferencing, (2) answers to questions can be seen by all learners in a computer conference (consider that instructors typically answer the same question many times), (3) materials on-line line can be easily modified and reused once completed, (4) links on the web to many relevant materials can easily be created to add to the richness of the learning experience and (5) automated and rapid feedback from learning tools and answer evaluation programs can be employed. In each of these items, a cost benefit exists. For example, if students in large classes learn from each other, the need for an instructor and teaching assistant is reduced. Similarly, the other items in the above list reduce costs by either reducing instructor time or providing materials or tasks for learners to undertake that do not have to be explicitly guided by an instructor.

The role of the faculty in teaching ALN courses is the "guide on the side" model. Many faculty will have difficulty adopting this model due to long familiarity with the "sage" model. The "sage" model is traditional and cost effective for large classes and will not be given up lightly. Teaching in an ALN mode requires preparation of materials in advance, detailed attention to learner questions, facilitating peer-to-peer interaction and continuous guiding of learners. While these modalities are possible in a traditional instructional model, there are few faculty that prepare detailed materials in advance, or spend significant time in the "guide" model. Most still prefer the "sage" model, although many would not admit it. This paper presents a way to move to an ALN teaching paradigm and suggests benefits that will accrue to institutions and to faculty who move to ALN modes of teaching and learning.

What are the possible paradigms for on-line learning? Can a case be made for using the ALN paradigm either exclusively for some types of learners or as an adjunct to traditional instruction? What are the ways to implement on-line courses? What organizational structures are possible? How well does ALN scale-up; should ALN be combined with synchronous methods? The study described below begins to give some answers to these questions.

\section{BACKGROUND}

\section{A. What is currently known about on-line learning?}

The way learners acquire knowledge in on-line settings has not been extensively studied. Most current use of ALN transfers traditional classroom/lecture-based methods to the ALN setting, recasting reading into web-based materials, lectures into on-line lecture notes or video clips and discussion into on-line conferencing. While these methods are effective in permitting time and place shifting of learning, there has been little examination of the "art of the possible" in the ALN 
medium -what are the ways to optimize learning, lower costs and provide convenient anywhereanytime learning?

What are some things that we have learned about ALN-based education? There are a fairly large number of schools experimenting with ALN for delivery of on-line courses. Students who take courses in this mode, like the experience. Scaling up seems possible. Faculty efforts in creating the on-line courses range from syllabus creation to building extensive on-line interactive materials. ALN materials are reusable. Experiments show that significant faculty time savings can accrue through materials reuse. Significant competition to universities from the commercial sector is already beginning to be observed. Many universities see this competition and are creating their own on-line learning networks to reach out beyond their traditional boundaries. Broadcasting of lectures remains, in the faculty view, as the most easily implementable method for on-line learning. Faculty at universities, in general, are not yet well acquainted with the many other possibilities for on-line learning and how ALN may impact their teaching strategies. There is considerable sympathy among the faculty for real-time video methods that perpetuate the now-stale lecture paradigm. ALN-based learning will change the way business is conducted in higher education. Luddites may warn that the lecture alone will continue to be the pre-eminent instructional technique. We doubt it.

\section{B. Who is Doing what in ALN?}

The panorama of ALN shifts on an almost daily basis. New announcements of courses, software, conferences, methods, etc. appear regularly, indicating the beginnings of a vibrant field. Most new things that happen are cataloged in the ALN Web [1] where materials about all facets of ALN are described. Listings of on-line courses, presentations from conferences, magazine articles about ALN and full research papers are included.

\section{Paradigms}

The major paradigms currently in use in ALN are listed below:

- Use of computer conferencing for:

- submission of homework

- discussion of issues

- help

- On-line materials that include:

- syllabus, assignments

- reading

- problems

- Interactive Learning Modules

- Course management

- homework submission and instant grading

- roll-ups of student progress

- Interaction with students

- e-mail

- listservs

- Audio clips of lectures

- real-time audio

- downloadable audio

- Video clips of lectures 
- real-time video

- downloadable video

Review of most courses currently on the Web reveal that few offer most of these features. Indeed, more than a cursory look reveals that many courses on-line consist of little more than a syllabus and a list of assignments. Some universities that have taken the lead in on-line course development (e.g., the University of Illinois [2], Drexel [3], NYU[4], Vanderbilt [5]) have courses that contain more extensively developed materials.

\section{Issues}

There are many issues that bear on the success of ALNs. Listed below are some that are among the most often discussed. The issues listed below are discussed in more detail at the end of the paper.

- Synchronous vs. Asynchronous on-line learning. The issue is what is the most appropriate form of on-line learning? Do "talking heads" provide value in learning? How much, if any? Can all materials that are delivered in a lecture be transferred to text, demonstrations, etc.? If yes, what is the cost? Are there proper mixtures of the use of synchronous and asynchronous learning methods? When is each appropriate?

- Scale-up. How does on-line learning scale-up? We understand how the intimacy of small classes is lost as class sizes increase in the standard lecture paradigm. We also understand the scalability of broadcast video lectures. However, we do not understand how ALN-presented courses scale. Early anecdotal results seem to indicate that scaling is better than in the traditional lecture; however, definitive studies have yet to be undertaken. Can scaling be accomplished through the engagement of non-collocated groups of learners; can group projects be undertaken on-line and how can the results of projects be viewed and graded?

- Costs. The cost of developing an ALN course is high if the course requires development of extensive materials and if running the course requires many on-line assistants for discussion with students. The most effective ways of lowering costs without sacrificing the quality of courses have not yet been systematically examined.

- Evaluation. Unfortunately, most evaluation of ALN courses, to date, has been conducted simply through collecting surveys of student satisfaction (... did you like? ....). Virtually no detailed quantitative evaluations have been conducted that collect hard data that included performance evaluations. Many college courses cannot be easily split into experimental and control groups. Further, we observe that many faculty are not eager to engage experimental situations in which a control group can be compared with an experimental group. Hence, more subtle forms of evaluation may well have to come about - for example, measuring the overall success of students, grades, jobs taken, etc.

Next, various methods for implementing ALNs are discussed as a prelude to focusing on how to secure answers for the issues posed above. 


\section{METHODS}

This section of the paper examines current methodologies for implementing ALNs, including a listing of the more popular currently available technologies. Mappings between the lecturecentered classroom and ALN-enabled courses are described. Finally, techniques for matching ALN capabilities to different teaching and learning styles are examined.

\section{A. Steps in Creating an ALN Course}

Listed below are the major steps that are frequently used to create an on-line course. The steps shown are the minimum.

- Create a Web page

- Include: syllabus, reading materials, assignments

- Add computer conferencing, including discussion groups and a help desk

- Link conferencing and web page assignments

- Add testing and course management tools

- Provide evaluation, both formative (to improve the course) and summative (to judge its effect). Surveys and performance evaluations are possible tools.

\section{Asynchronous methods}

The most straightforward way to provide information to learners is by constructing web pages that can be viewed anywhere and at anytime. Starting with a course outline, each on-line module can link to the actual reading materials or simply listed as reading assignments in a textbook. Audio and video clips can be embedded in web materials as can interactive learning modules (e.g., simulations). Conferencing provides a way for learners to hold discussions and submit homework.

\section{Synchronous methods}

Synchronous methods are those that require that learners participate in a learning event at a specific time. These methods include on-line chat, listening to a live audio or video broadcast, and telephone, including conference calls. Of course, the traditional lecture falls in this category.

\section{Implementation Tools}

Six classes of implementation tools are listed below. Links to these tools are given in the references for this paper.

\section{- Authoring}

Authoring tools include a variety of editors which can be used to create Web pages. These range from free tools such as provided by Netscape (Netscape Gold) [6] and add-ins to Microsoft Word [7] to full Web development tools such as FrontPage [8]. Our experience is that full Web development tools such as FrontPage provide authors with the highest productivity.

\section{- Conferencing}

Several excellent conferencing tools are available. Probably the best known are Lotus Notes [9], First Class [10] and WebNotes [11]. Lotus Notes is a full featured system that is integrated with the Web. FirstClass provides both synchronous (i.e. chat) and asynchronous capabilities. More recently, Allaire Forums [12] has provided an excellent entirely web-based conferencing system. Netscape [13] and Digital Equipment [14] also 
provide conferencing systems. Those who wish to include conferencing in their on-line courses are counseled to examine the characteristics of each possibility carefully.

- Multimedia Tools

Multimedia can be included in on-line courses. Audio recordings can be delivered as downloadable clips or made instantly available using programs such as RealAudio [15]. Likewise, video can be provided using RealVideo [15]. The showing of Powerpoint slides with accompanying audio can be achieved using ActiveX plugins [16] for web browsers or by converting Powerpoint slides to HTML pages.

- Simulation Tools/Interactive Learning Modules

Interactive simulations and learning modules can be implemented on the Web using various types of software, including Visual Basic 5 [17], Java [18], PowerBuilder [19], Toolbook [20] and others.

- Testing Tools

Few on-line testing tools currently exist. One was created by Stanford Testing [21].

- Management Tools

The number of management tools for on-line courses is also sparse. One is CyberProf [22], created at the University of Illinois and being readied for commercial application. For determining who has visited the course, which pages they have viewed, etc. a commercial product is made by Marketwave [23].

\section{B. Matching ALN to Pedagogy}

Should traditional classroom-centered learning methods be exported to ALNs? Or, should teaching and learning methods be adapted to the capabilities of ALNs? Many college-level instructors strictly adhere to the "learning by being told" model of instruction. This model is economical for the lecturer but rarely very useful for the learner. Exporting the traditional lecture technique to an ALN format is straightforward since lectures (both video and audio) can be easily recorded and then viewed on-line. However, people who view these on-line lectures typically remark that the lectures presented in this format are not very useful. Just as in the traditional classroom that is run as a strict lecture, little learning takes place when learners do not interact with the instructor, each other or active learning sources.

"Learning by being told", "learning by doing", "learning by reading and searching the literature", "learning by discussion and debate" are pedagogical constructs used in varying degrees and in different ways in different disciplines and in varying amounts. For example, it is common practice in undergraduate education to have lectures two or three times a week and a laboratory or discussion period once per week. In a typical lecture given in engineering education, there is little discussion. In the laboratory, students learn by doing experiments. Engineering students will almost always express the sentiment that they learn much more in laboratories than in lectures. Many liberal arts courses make "lecture" sessions into discussion and debate and engage students directly.

Table 1 compares some of the common teaching paradigms and indicates which are likely to be most successful in an ALN implementation. 


\begin{tabular}{|l|l|l|l|}
\hline \multicolumn{1}{|c|}{ Paradigm } & \multicolumn{1}{|c|}{ Traditional Use } & \multicolumn{1}{c|}{$\begin{array}{c}\text { ALN } \\
\text { Implementation }\end{array}$} & \multicolumn{1}{c|}{ Likely success with ALN } \\
\hline $\begin{array}{l}\text { Learning by } \\
\text { listening }\end{array}$ & $\begin{array}{l}\text { Lectures: very common; } \\
\text { succeeds with dynamic } \\
\text { lecturers; students bored } \\
\text { with dull "sage" }\end{array}$ & $\begin{array}{l}\text { On-screen video } \\
\text { played on-demand or } \\
\text { downloaded }\end{array}$ & $\begin{array}{l}\text { Fair to poor. Suffers from lack of } \\
\text { presence of the "sage." However, } \\
\text { permits replay, indexing of lecture. }\end{array}$ \\
\hline $\begin{array}{l}\text { Discovery } \\
\text { learning }\end{array}$ & $\begin{array}{l}\text { Library, literature } \\
\text { searches; }\end{array}$ & Web searching & $\begin{array}{l}\text { Web searches are often much better } \\
\text { than traditional library searching }\end{array}$ \\
\hline $\begin{array}{l}\text { Learn by } \\
\text { doing }\end{array}$ & $\begin{array}{l}\text { Laboratory. Works very } \\
\text { well in traditional model. } \\
\text { Writing, creating things. }\end{array}$ & $\begin{array}{l}\text { Learning modules, } \\
\text { simulations on-line; } \\
\text { writing on-line, } \\
\text { critiquing }\end{array}$ & $\begin{array}{l}\text { Learning modules can be very } \\
\text { good, but on-line laboratory } \\
\text { materials are not yet widespread. } \\
\text { ALN is an excellent medium for } \\
\text { writing and critiquing. }\end{array}$ \\
\hline $\begin{array}{l}\text { Learn } \\
\text { through } \\
\text { discussion } \\
\text { and debate }\end{array}$ & $\begin{array}{l}\text { Poor in large classes, } \\
\text { excellent in very small } \\
\text { classes with the right } \\
\text { instructor }\end{array}$ & $\begin{array}{l}\text { Network } \\
\text { conferencing }\end{array}$ & $\begin{array}{l}\text { Scales up to many learners; } \\
\text { potentially much richer than } \\
\text { classroom discussion }\end{array}$ \\
\hline
\end{tabular}

\section{Table 1: Common Teaching Paradigms}

Another way to view how to implement ALN is to consider how an ALN course is to be conducted. Table 2 displays the typical things that are done in traditional courses and lists how these activities can be implemented in an ALN setting.

There are a variety of technological supports available for implementing ALNs. The major question an instructor should determine at the outset is the style of class that is to be implemented. Some possible characteristics of a traditional lecture course are given below. Some characteristics are more relevant in one field than another. For example, "problem solving" and "constructing things" is found most often in engineering.

\begin{tabular}{|l|l|l|}
\hline Activity & Knowledge Type & ALN Implementation \\
\hline Imparting facts & L, I & $\begin{array}{l}\text { Web Pages, Learning Modules, RealAudio, on-line } \\
\text { video }\end{array}$ \\
\hline Discussion /Debate & L, I, E, P-P & Conferencing, E-mail \\
\hline Problem Solving & E, A & $\begin{array}{l}\text { Web, Learning Modules, Conferencing, Computer } \\
\text { checking of problem solutions }\end{array}$ \\
\hline $\begin{array}{l}\text { Critical Thinking: } \\
\text { writing, discussions }\end{array}$ & E & Conferencing, posting, critiquing on-line \\
\hline Constructing things & A & Web Pages, portfolios, Websites \\
\hline Performance & L, I, A,E & Portfolios demonstrate performance \\
\hline
\end{tabular}

$\mathrm{L}=$ literal, I= inferential, $\mathrm{A}=$ applicative, $\mathrm{E}=$ evaluative, $\mathrm{P}-\mathrm{P}=$ peer to peer; see [24] for details of these knowledge types

Table 2: Implementation methods by Activity

\section{Issues}

A core issue is to determine when ALN is useful and when it is not. When students and instructors can meet together in small groups, are continuously accessible to each other in a face-to-face setting, and cost is not a concern, ALN would not likely be the instructional paradigm of choice. For example, small classes in liberal arts colleges or students living in proximity in a dormitory would not be expected to benefit greatly from ALN. However, as classes grow larger and as 
learners require access to learning at different times and in different places, ALN appears to have clear advantages over the traditional learning model. Also, when knowledge in a field is distributed across the world and learners come from anywhere, ALN can greatly improve the richness of a course by bring diverse people together electronically. A wide variety of issues remain to be resolved that include how to: (1) impart the "closeness" of an intense face-to-face interaction to ALN,(2) scale up ALN to support large numbers of learners participating asynchronously, (3) reduce the high level of effort required to create ALN courses and (4) create support tools that are intuitive and straightforward that faculty can use.

\section{The Face-to-face problem}

It is obviously clear to the professoriate that interacting with students in very small classes produces excellent results. The ability to discuss issues, dissect problems, work through questions and engage in free association is far better with a small group of learners than in a classroom containing a large number of students. Face-to-face interactions permit a professor (leader, facilitator) to rapidly change the direction of the discussion and to directly satisfy the needs of the learners. The group can also rapidly interact and come to agreement. None of these kinds of direct interactions can be quickly accomplished using ALN modalities. Neither can these types of interactions be accomplished using video broadcast or point-to-point video interactions. Since faceto-face interaction of the type experienced in a small group is missing in current ALN-style courses, the question is what sort of ALN-style interaction could replace the small group experience? If the small group feeling could be brought to large groups, a significant improvement in ALNs could be achieved.

\section{Scaling up}

Scaling up is a problem to which ALN is thought to be well-suited. Extensive use of computer conferencing permits questions asked (and answered) to be viewed by larger numbers of people. Group work using conferencing permits interactions in a small group. Feelings of personalization can be provided by interactive programs (e.g., learning modules), testing on demand, rapid grading of homework and display of portfolios. While large classes in the lecture mode results in large numbers of students listening to a speaker, interaction among the people attending the lecture remains very limited. ALN breaks that barrier by permitting the entire group of learners to view and discuss materials on a conferencing system. Further, it permits students who are either too shy to participate in large group discussions or are hampered by language constraints to become active. Hence, we hypothesize that scale-up is possible and readily achievable using ALN. Studies are currently underway to test this hypothesis.

\section{EXAMPLE COURSE}

This section describes a course taught at Vanderbilt University that was designed to test several hypotheses about the effectiveness of ALN paradigms. A number of research questions were asked at the outset; the course design was created, in part, to help address some of these questions.

\section{A. Research Questions}

- Are face-to-face sessions necessary or useful when students can come to class? Do students attend face-to-face sessions when it is guaranteed that there will be no information imparted that will not be accessible on the course conference? If yes, why? 
- Do the number of face-to-face class attendees diminish as learners understand more about the nature of an ALN course? The number of face-to-face attendees in a course question-andanswer session held at a scheduled time can be plotted as a function of the time into the course. The research question is whether students find they can use only the on-line information after they understand how to use the course. A series of plots constructed over a period of semesters can be used to gauge how well an institution is moving into the ALN modality.

- Are there differences in the way that women and minorities use the course? For example, do women and minorities find the anonymity of computer conferencing a benefit? This information can be extracted directly from the conferencing postings.

- Are foreign students more satisfied with this model of instruction? Do non-native English speakers excel in this environment?

- In a closed conference created for team activities, do student teams really use the conference? Can the extent and type of use be measured?

- Students typically use email; will the number of emails that they send to the instructor decrease as they begin to use web conferencing?

- Is student performance as good or better than in a traditional lecture?

- What do students say about the course? This assessment can be implemented by on-line surveys. What is learner performance on pre and post tests? Tests should be designed to test their knowledge of the subject matter studied.

- How many students engage in peer-to-peer learning? Will peer-to-peer learning increase? The number of peer-to-peer interactions by week can be measured and plotted.

- Which types of students emerge as team leaders and is that leadership manifested on the private web conferences?

- Does the use of mentors for assisting student project groups improve student performance? What is the experience of the mentor and the student group; is the interaction useful for both?

\section{B. ALN Course Design}

The features listed below were incorporated in an ALN course designed to help answer some of the above questions. Many of the design features were based on student feedback from the offering of this course in a previous year.

- An explicit statement of what learners should do each day that they are enrolled in the course was made explicit by creating a detailed web page that contained complete directions, reading assignments and group assignments, questions to be answered, help and hints. A preliminary trial of the course showed that students preferred to know precisely what is expected of them each week and that this information should be in one place only.

- Each assignment pointed directly to the questions that are to be answered on the web conferencing system. In this way there was no ambiguity about which questions were the ones to answer for a given week.

- All materials were available in textbooks and on the web. Explicit assignments were made for all materials available; e.g., "read pages 3 to 52 this week and answer the following questions".

- A public conference was available for help and questions.

- Private conferences were available for each student project team of 4 to 5 people. 
- Questionnaires were available for formative and summative assessments.

- Students were required to maintain portfolios that contain all work that has been completed.

- Assessment was made by examining the private conference, portfolios, and submitted questions. The metric use for evaluation was a range from excellent to poor. A reduced grade was given for materials not turned in on-time. On-time was defined on a weekly basis. Strictly speaking, a "pure" ALN course would not have any time restrictions. However, in a university environment in which grades are required at the end of each semester, some timing is required.

- Project teams were created before the class started; each project team included an alumnus or industrial representative who interacted entirely using web conferencing with students on the team. The outside members of the project teams acted as mentors.

- For projects, student teams were graded based on (1) the number of visitors to the website that the team created and (2) the number of features found in the website. This approach was selected to be able to quantify project outcomes.

- A virtual laboratory, in which students performed lab experiments and reported results was created.

- Optional face-to-face class meetings were held in which only questions were asked and answered and demonstrations given. Questions asked were posted on the class conference so that students who did not attend the face-to-face session were not penalized.

- Questions to be answered by students were available each week. Students posted answers to questions within a one week period. This semi-synchronous design was provided so that students could complete the course within the semester. Without explicit deadlines, many students would not complete the course. Further, to provide team interactions, weekly synchronization provided the possibility of similar questions being asked and answered on the course conference.

- The use of email to the instructor was discouraged. The reason is that most students ask the instructor the same questions. Hence, emails about course materials were returned with a note to post the question in the course conference in the appropriate thread.

- Peer-to-peer learning was encouraged. We explicitly stated that students who assisted other students would be rewarded with extra credit. 


\section{EECE 274/MT 274, Vanderbilt University}

EECE 274/MT 274 is a three semester hour course offered at Vanderbilt University to Juniors, Seniors and first year graduate students. The topic is "Informatics Engineering." Students in all disciplines in the School of Engineering took the course. Contents of the course include the basics of tcp/ip and how to create a website. Figure 1 shows the opening screen and Figure 2 the topics covered in the course.

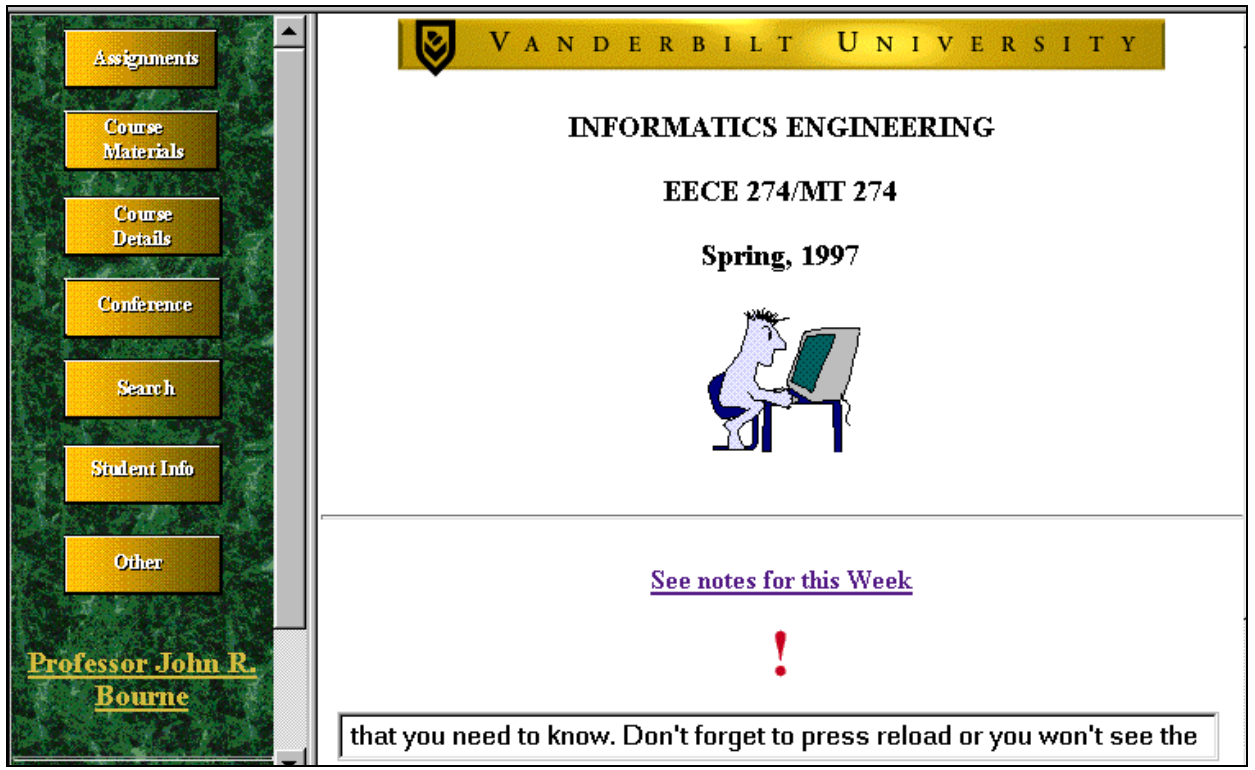

Figure 1. Opening Screen of the Course: Informatics Engineering 


\section{OOn-Line Materials}

On-line Materials:

- Introduction to Informatics Engineering

- Building your own homepage

- Information Tools and the Internet

- Take a Workshop on Using the Internet

- Read a paper on how to set up a server to serve a course

- Products for the World Wide Web

- Introduction to Network Protocols

- Visual Basic and Network Access

- CGI and Perl

- JavaScript

- Java.

- Knowledge Communications

- Products for Synchronous and Asynchronous Information Communication

- Information and Quality Improvement

- Informatics for Groups: Computer Supported Cooperative Work

- Meetings, Time and Understanding

- Computer Supported Cooperative Work

- The Role of Databases and Data Modeling

- Delivery and Marketing of Information Products

\section{Appendices}

- Winsock Specifications

- Tips for setting up Slip/PPP

- Usefil Resources

Figure 2: Topics in Informatics Engineering

\section{Course Organization}

The EECE274/MT274 course was offered entirely on-line. In the Spring semester, 1997, 83 Vanderbilt students completed the course for credit and 26 Vanderbilt alumni and industrial participants served as on-line mentors. Twenty five project groups of 4 or 5 people each were formed. Students created homepages that included their pictures. A separate page for alumni resumes and pictures was created. A main "Assignments by week" page was constructed that contained all the activities to be carried out by the students. Figure 3 shows a portion of this page. Assignments were listed on the "Assignment by Week" page for each week. This page specified reading in two textbooks, contained pointers to questions about the reading, pointers to the on-line laboratories and pointers to descriptions of the activities to be carried out by each project team. Two teaching assistants and two graders graded the answers to questions submitted on the computer conference each week. 


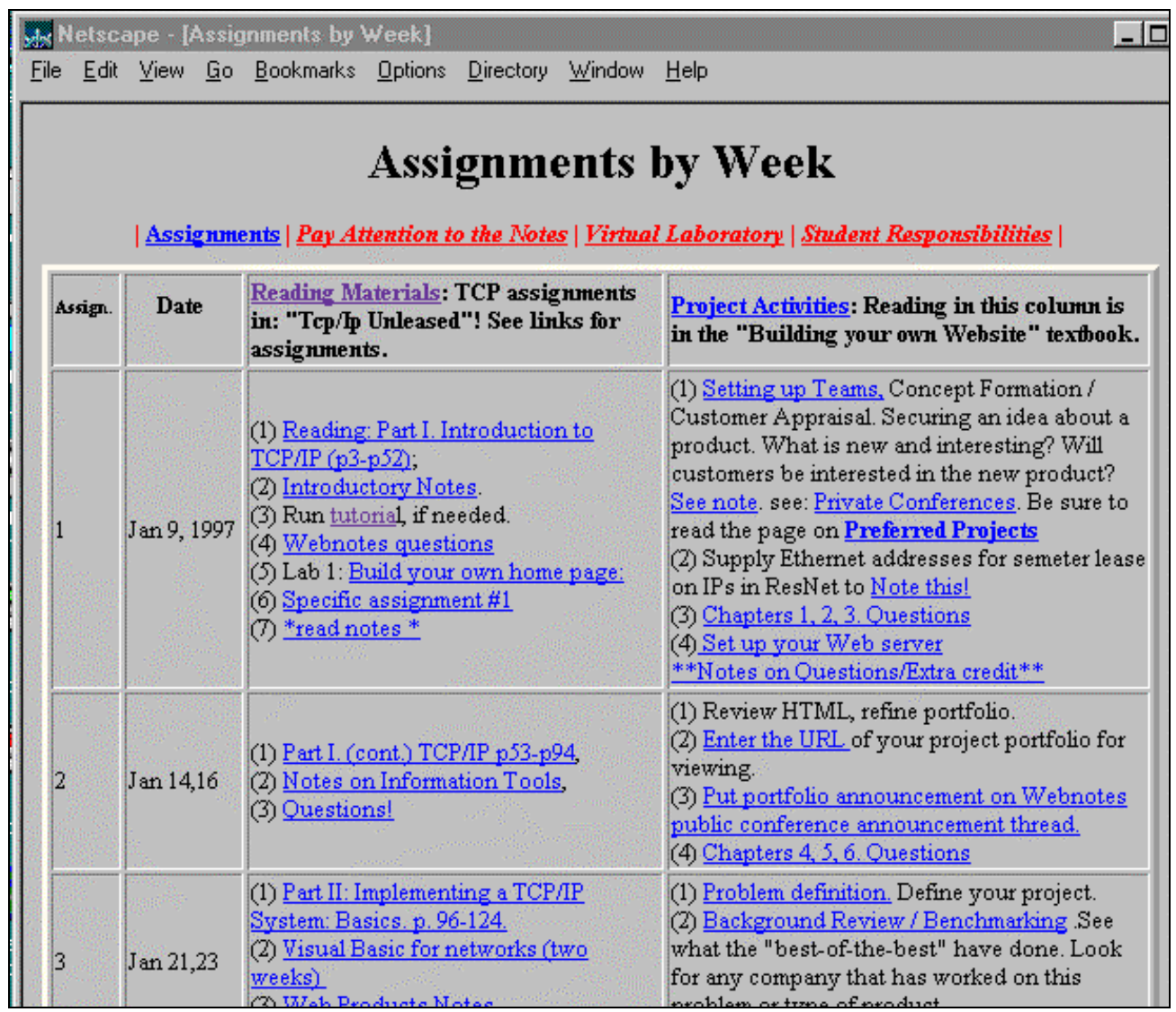

Figure 3. The Assignments by Week Page

The objective of the project activities was to create a website with a variety of features (e.g., server-side push, counters, log assessment, animation, activeX controls, Visual Basic simulations, etc.). Grades were assigned based on (1) the number of features implemented and (2) the number of visitors to the site outside of Vanderbilt. The idea of the latter metric was to get students to create a site which would attract visitors worldwide. Most projects were of the "intellectual capital" type, (e.g., an on-line workshop, tutorials, how to use activeX). The performance outcome of the course was to create attractive websites with high intellectual capital which would attract "customers." All projects were required to be technical in nature, if possible.

\section{Features of the Website}

The website for the course is located at http://jrbnt.vuse.vanderbilt.edu/274/. The site contains a guestbook, a search engine, demonstrations, a real-audio welcome, cgi-feedback forms, pointers to student portfolios, and pointers to all assignments. A web analysis system is used to determine visitors to the site. The actual system used is called Hitlist (http://www.marketwave.com/). Hit list provides a roll-up of pertinent information that includes the number of visitors, who visited, who visited what pages, and what sites visitors were referred from.

\section{Computer Conferencing Methods}

Figure 4 shows a typical computer conferencing screen; each line is a main discussion or submission thread. The course conference contained (1) questions for students to answer, (2) a help desk for general help, and (3) discussion topics. The conference was moderated (i.e., no responses 
could be viewed until a moderator reviewed and unhid a comment). Also, private conferences were set up for each project team of 5 people. Each project team was required to exhibit its work on the main conference in a team portfolio.

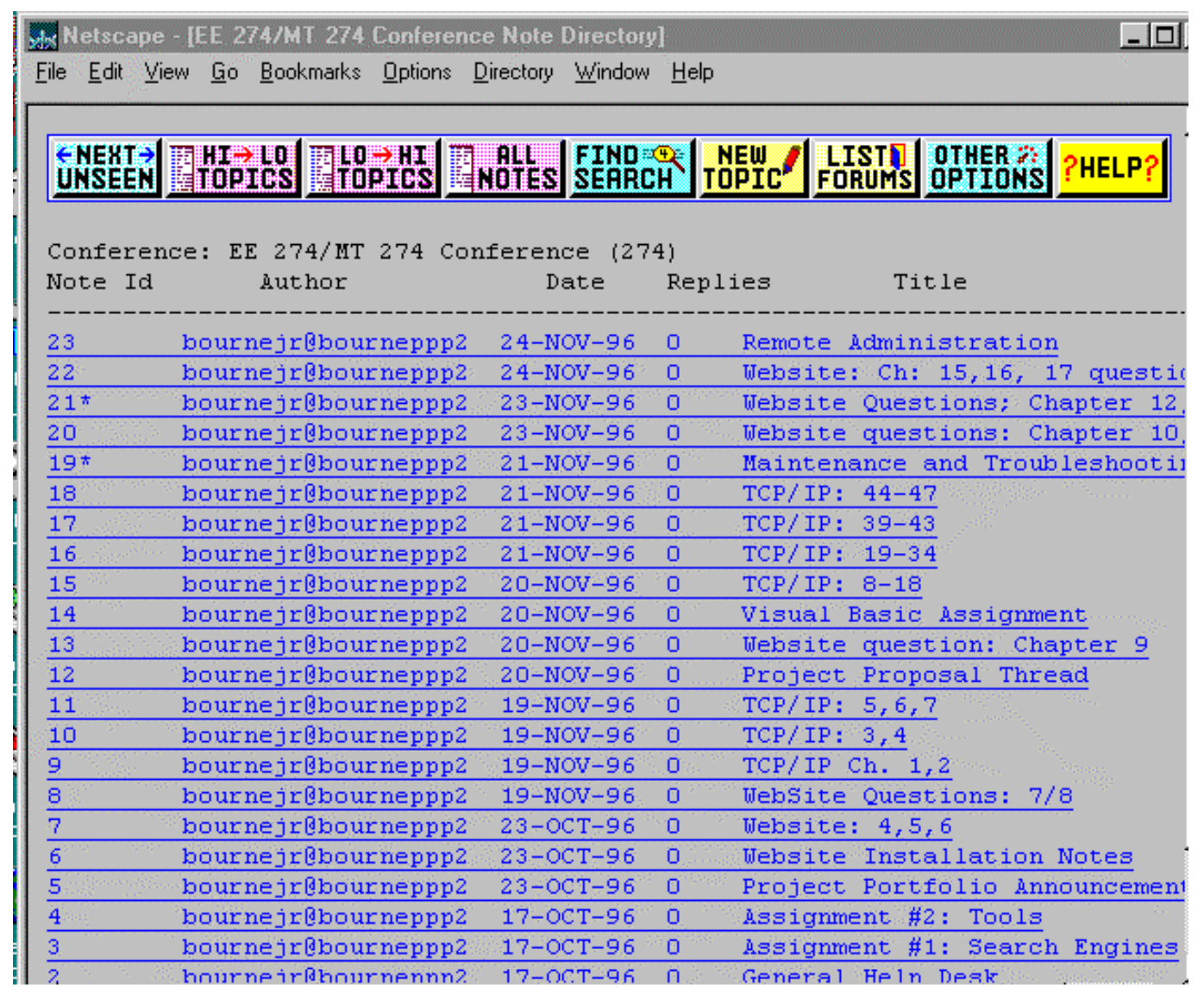

Figure 4. The Computer Conferencing System

\section{Information Management Methods}

Viewing of the main course materials did not require a password. Use of the WebNotes conference did require a password, which could be obtained by self-registration. The access log analysis program HITLIST was used to track time and topic visitation.

Figure 5 displays how information and activities are organized in the course. 


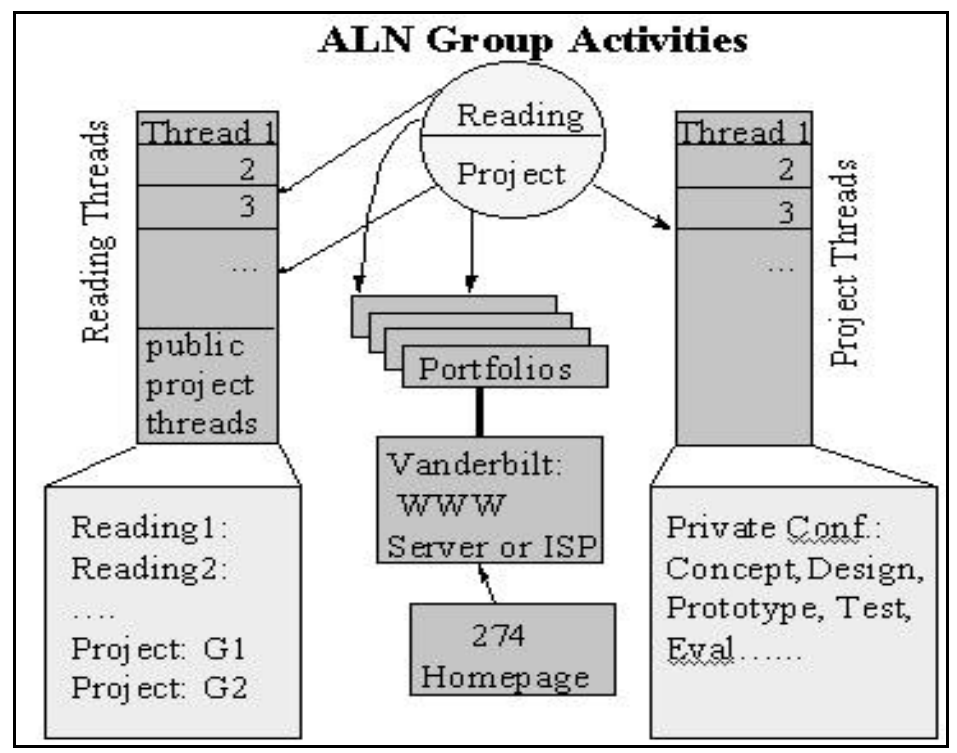

Figure 5. Organization of Information and Activities

\section{RESULTS}

Sixty two students pre-registered for the course. Sixty three added during the first week of the course and during the next 8 weeks, 42 dropped. Eighty three students completed the course. The average grade for students in the course was 79 , which corresponded to an average grade of $\mathrm{C}+$.

An on-line pre-test and post-test containing the same questions was given at the outset and at the end of the semester. The test contained 27 fairly difficult multiple choice questions. Fifty three paired tests were secured from students who completed both the pre and post test. The average on the pre-test was $47 / 100$ and the average on the post-test was $75 / 100$.

During the semester, few students attended lecture sessions after the first few class periods, preferring the ALN mode. There were no observable differences in the way men and women used the course materials. Non-native English speakers were observed to performat least as well as English speakers. Students who lived together in the same dormitory did not want to use their computer conference. Conversely, private conferences were useful for non-collocated teams.

In general, students liked the fundamental concept of learning anywhere and at anytime. Measuring student usage of the course shows that students do, in fact, shift their learning - often to the middle of the night. Students appear to learn as much or more as in traditional lecture-based courses; however, we have no data yet that verifies this anecdotal observation. Further, scale-up appears possible. Offering a course via ALN to several hundred students should require fewer coaching resources than a traditional offering. Yet, ALN courses are hard to construct and require significant time investment by the faculty. Buy-in from the average faculty member is lukewarm; faculty do not want to change to a methodology that requires more work and has outcomes that are not much better than what they are currently doing. However, ALN courses are reusable and faculty/facilitators using ALN materials find it much easier to offer a course a second time or offer a course to students in multiple sections of a course. 
Students in the EECE 274/MT 274 class were quite enthusiastic about working with alumni in their project teams. The capability of including alumni or other industrial participants would not be possible without ALN. Students initially commented on the structure of the course and appreciated the explicit statements about what their tasks would be each week. However, as the semester progressed, many wanted the assignments revealed only on the week prior to the due date. The ALN nature of the course permitted rapid updating of the materials so that all students, alumni, and teaching assistants could see the changes.

The EECE274/MT274 course has been offered for several years, paralleling another ALN course at Vanderbilt offered to first year engineering students. In both courses, the reuse of materials has been a distinct advantage for the instructors. An on-line editor in both cases permitted instructors and TAs to rapidly update and reuse materials, building from year to year. Detailed analysis of the outcomes of offering this course will be available in a subsequent paper.

The lessons we learned during the semester from offering the course are summarized in the table below:

\begin{tabular}{l} 
Lessons Learned \\
\hline Students procrastinated more than in non-ALN courses - "out of sight, out of mind" \\
\hline Students learned as much as in traditional courses \\
Eighty percent of the students liked ALN; twenty percent felt uncomfortable without the traditional \\
lecture \\
\hline Conferencing is important; encouraging peer-to-peer learning works \\
The course contained too much material. Students were not impressed by having encyclopedic \\
knowledge at their fingertips to help them learn; they simply wanted to know what information \\
they were responsible for! \\
The use of mentors worked well in about half the teams. More experimentation is needed.
\end{tabular}

Next, we provide a prognosis for what prospective outcomes may be for ALN, both in the near and longer term.

\section{Discussion}

The experiments undertaken provided some insight into some of the issues raised at the outset of the paper. We now understand more about scale-up and cost-related issues and have some better appreciation of the mechanisms for measurement and evaluation. The only concrete finding about synchronous vs asynchronous education was in the finding about how a face-to-face session was used.

Synchronous vs. Asynchronous. We determined over the course of the semester that students, when given the option, will not come to class unless there is something happening in the class that will directly impact their grade. We designed the face-to-face sessions such that students accessing materials would not be at a disadvantage. As the semester progressed, we found that once students understood that materials provided at the face-to-face question and answer session were available on-line, they stopped coming to class. Further, they started submitting their questions asynchronously. Students in project teams often met at class time for a face-to-face session since that time was pre-scheduled. 
Scale-up and cost. We determined that running a class of 83 with one instructor, 2 teaching assistants, 2 graders and 25 remote mentors was an effort similar to running a face-to-face class with about half as many participants. Mentors were unpaid, and are not part of the cost of the course, beyond the effort to secure their help. We predict that we could possible handle 150 students with the same teaching complement.

Evaluation. The metrics used for evaluation were fairly effective. The portfolio schema was very useful. Submission of homework on the computer conference was effective. Private conferences for the project teams were not used as much as we hoped. Reduced activity in this area was probably dominantly cultural. We found that many did not want to leave an email-only environment. Metrics employed provided a useful way of assigning grades.

\section{Near term outcomes}

In the upcoming two years, there is likely to be a greater awareness of the potential of ALNdelivered courses among faculty. Administrations in universities are pushing to make faculty understand the nature of change that has been brought about by the World Wide Web and how it will affect their teaching and student's learning. Students are coming to college with significantly enhanced computer skills. These students are demanding use of network connections and expect that courses will be offered on the web. There is likely to be little tolerance for only "chalk and talk" much longer except at residential colleges with small classes. The intimacy of the small seminar discussion will be difficult to achieve in ALN settings. On the other hand, ALN makes possible small discussion-oriented groups where only a few learners worldwide are interested in a topic.

\section{Long term outcomes}

By the early part of the next millennium, the use of on-line delivery of courses will become as ubiquitous as the presence of networks in the dormitories in 1997. The widespread adoption of campus network formed the basis for dramatic change in the way education is delivered. Faculty must adapt to changed modes of instruction. "Chalk and talk" alone will likely become obsolete as it becomes clear that advanced ALN will provide much more inviting and useful learning environments. By advanced ALN, we mean the combination of anywhere-anytime learning with interactive learning modules, record keeping, immediate feedback and virtual learning realities in a cost-effective system

We can expect most universities to begin to try to reach new audiences to expand their potential customer base. For most universities this expansion will need to be into the industrial sector since the current university cohort covers mostly college age learners. Competition among institutions will force some institutions to retreat to a purely residential non-ALN mode or to go out of business. Larger, more well known institutions will become more pre-eminent and force lesser institutions into niche markets. This change will have a particularly devastating effect on the highpriced privates and the lesser-known publics. ALN will become pervasive and it will quickly become apparently that content will be the driver that distinguishes one university from another. For example, molecular biology could be taken from the world's premier department or from an unknown faculty member at an unknown university. Should leading universities decide to pursue ALN on a national level, the current model of many universities distributed throughout the land could become obsolete. The latter is not likely to happen, however, since colleges will remain the place that young adults go to grow up and interact. For older adults continuing education may well become a very large activity that can be served by the university ALN cohort. As job demands 
rapidly require retraining, relearning and reworking knowledge, continuing education is likely to receive a significant boost in the upcoming years.

\section{Research needs}

The above prognostications may seem a bit presumptuous, yet we feel that many of these forecasts have the potential to come true. However, ALN will not be a significant player in organizational change unless fundamental questions are dealt with. For example, it is essential that knowledge organization mechanisms be understood and that tools be created that will assist faculty in linking their knowledge to an ALN world. Management tools for webs including registration methods, rapid feedback, test taking, authentication and a host of other techniques and technology that must be worked out before ALN can gain wide-spread acceptance. Virtual learning communities will ultimately provide the ability to work and learn with people who might be anywhere. It will require significant research to understand the best ways to accomplish the goal of providing excellent anywhere-anytime learning experiences.

\section{ACKNOWLEDGEMENTS}

This research was supported by several grants from the Alfred P. Sloan Foundation, the Center for Innovation in Engineering Education and the Vanderbilt University School of Engineering. Special thanks are given to Dr. A. Frank Mayadas of the Sloan Foundation for stimulating discussions about the nature of ALN over a multiple year period.

\section{REFERENCES}

The references below are in hypertext format, containing links to the materials specified. Each link should be preceded with http://.

1. The ALN Web. www.aln.org/

2. The Sloan Center at University of Illinois. w3.scale.uiuc.edu/scale/

3. Drexel University. www.sloan.org/education/trestee/Drexel2.html

4. New York University. www.sloan.org/education/officer/NYU.html

5. Vanderbilt University. ciee.vuse.vanderbilt.edu/ciee/

6. Netscape. www.netscape.com

7. Microsoft Word. www.microsoft.com/msword/

8. FrontPage. www.microsoft.com/frontpage/

9. Lotus Notes. www.lotus.com

10. First Class. www.softarc.com

11. WebNotes. www.spyglass.com

12. Allaire Forums. www.allaire.com

13. Netscape Conferencing. www.netscape.com/comprod/products/communicator/index.html

14. Digital Equipment. www.altavista.forum.digital.com

15. RealAudio and RealVideo. www.real.com

16. ActiveX. www.microsoft.com/activex

17. Visual Basic 5. www.microsoft.com/vbasic

18. Java. java.sun.com

19. PowerBuilder. www.powersoft.com

20. Toolbook. www.asymetrix.com

21. Stanford Testing. www.testprep.com 
22. Cyberprof. www.oir.uiuc.edu/etag/news/physics/hubler/hubler.htm

23. Marketwave. HitList. www.marketwave.com

24. Bourne, J. R., Brodersen, A. J., Campbell, J.O., Dawant, M.M and Shiavi, R. G. A Model for On-Line Learnng Networks in Engineering Education, Journal of Engineering Education, ASEE, Vol 85, No. 3, pp 253-262, July, 1996 